\title{
Parental Suggestions for Facilitating Acceptance and Understanding of Autism
}

\author{
Bernie Wastney \\ Gayle Te Kooro-Baker \\ Carolyn McPeak
}

\begin{abstract}
This article contains the transcript of a session one mother ran in her child's class. The aim of the session was to give class members a better understanding of autism spectrum disorders (ASD) in general and of her son in particular. The effectiveness of her approach is evident in the follow-up stories children wrote and in the experiences this mother recounts. Included as an appendix is a questionnaire developed by three Māori parents of children with ASD. These questions were used to assist them in selecting schools to meet their children's special and cultural needs.
\end{abstract}

\section{Storied Experience \\ Keywords \\ Asperger syndrome, autism spectrum disorders, culturally appropriate strategies, inclusion practices, Māori culture, parent participation, parent school relationship, peer acceptance, school choice, whānau.}

\section{INTRODUCTION}

All parents are hopeful that their child's school years will be both happy and successful. Many also assume that this will happen without a huge input on their behalf. For some parents of children with ASD this assumption is a luxury. Their experience has taught them that in order for their child to cope with even the simplest daily tasks, they need to invest a great deal of time and effort into ensuring this happens. Even in the best of schools children with ASD may not be readily accepted by their classmates. To help facilitate acceptance and understanding of her son Michael when he first started school, his mother Bernie explained his disability and strengths to his new classmates. In following years, Bernie consulted with Michael's new teachers and together they considered whether there were children who were puzzled or frightened by Michael's behaviour and whether the new class would benefit from Bernie talking to them. Following is the transcript of a talk Bernie gave to Michael's year 4 class. Michael had an important role to play in this session, demonstrating his special abilities and unique ways of communicating.

\section{SOME LAMPS ARE AUTISTIC}

Props used:

- 2 table lamps (identical looking but one plug in and one touch lamp)

- Books with characters that Michael could identify (to show off his skills)
- ANZAC biscuits that Michael had made (to show off his skills)

- Māori reader book (Māori language book read by Nan)

- Teacher Aide who used sign language to children

- Extension cord and double plug

- Reading Master books that Michael loves and knows.

Kia ora everybody, my name is Bernie and I am Michael's Mum, and this is my Aunty who is going to read us a story later, but you can call her Nan, Say "kia ora Nan", and of course you all know Michael's teacher aide Mrs C and she's going to tell us a story.

Let the children see that in their class some children can do some things but not do other things.

There are some people with autism who can do some things, but not do other things.

I wanted to speak to you all today about why I think Michael is so special.

Michael has autism, but before I talk about him, I'd like to know a little bit about you.

Q. Hands up all those children who can ride a bike. (wait for response)

Q. Hands up who can't ride a bike. (wait for response)

Oh, there are some children that can ride bikes and some children that can't.

Q. Hands up all those children who can do a cartwheel. (wait for response)

Q. Hands up who can't do a cartwheel. (wait for response)

Oh, cartwheels are hard to do and there are some children who can't do them.

Q. Hands up all those children who can swim. (wait for response)

Q. Hands up who can't swim. (wait for response)

Great, most of you can swim, but there are some who can't.

Q. Hands up all those children who can tell me what $10 \times 10$ equals.

What a clever class! 
Q. Hands up all those children who know what $25679 \times 29309$ equals.

Well even I can't do that, can you Nan?

Can you [Teacher's name]?

Can you [Teacher Aide's name]?

Well, none of us can, but do you know there is a boy with autism in our city who is the same age as Michael who would be able to answer that question straight away without even using a calculator? Yet this boy can't tie his shoelaces and he can't talk and he doesn't like it when you touch him, and doesn't like it when you talk to him.

Michael has something called autism. Who knows what autism is?

Well everyone who has autism is different.

Some people with autism can talk, and some can't talk.

Some people with autism can understand what people are saying, and some can't.

Some people with autism can read and some can't, and some can swim and some can't.

Do you know that even the best doctors and scientists can't agree on what autism is, or why some children have autism?

\section{Lamp Experiment}

Lamp experiment may help explain that even though the lamps look the same, they work differently. An opportunity to explain why Michael needs a teacher aide, who touches or prompts him to help him work and why they use chippies or special toys as positive reinforcement to encourage work or co-operation.

Sometimes I wonder if it is like a lamp, let's try an experiment.

Q. What happens when I plug in this one?

(plug in first lamp - plain one)

That's right, when I plug it in, the lamp turns on.

Q. And what happens when I plug in this one?

(plug in touch lamp)

Oh no, it didn't work even though I plugged it in, I know, lets try touching it.

(Touch lamp)

Wow, this lamp turned on when we touched it, it just needed some help to get going.

Inside the first lamp there is a set of wires, and when you plug in the lamp and turn on the switch the wires join and the light goes on.

Nobody is really sure, but I think in Michael's brain, it's kind of like the second lamp that doesn't go, even when you plug it in, so maybe the wires in Michaels brain just aren't quite touching and they just need some help to get it going. Michael is kind of like that, his teacher and teacher aide sometimes have to touch him or say something that helps him to switch on.
Q. Has everyone seen Michael's teacher aide give him chippies? Why do you think that is?

She uses them to encourage Michael to do things, she might say, "Michael, finish off this work, then you can have a chippie".

That's similar to what your teacher says. Sometimes they might say, "Finish off your writing, then you can have a snack from your bag, or when the room is tidy, you can go to lunch."

At home, your Mum might say, "Eat up your dinner, meat or vegies, then you can have dessert or ice cream."

Show children some of the things that Michael is good at and some of his special interests and simple ways that the parents or the teacher aide use to communicate with him.

I like to think that people with autism are really special. There are some things they can do, and there are some things they can't do, just like most of you here.

Well, there are some things that Michael can do, and some things that Michael can't do.

Q. Who can tell some of the things Michael can do...?

When Michael wants his teacher aide to go with him he can say "Up" or "Come me."

Sometimes you can get him to do things by saying "Do this!" "Look!"

(demonstrate Michael copying, touching nose, clapping, blowing kiss etc.)

Shall I show you some of the other things that Michael can do?

Michael loves to help do the baking, and he made these beautiful biscuits last night.

We are going to leave them here for everyone to have for morning tea.

Michael likes to watch Barney, and he knows the words to every song that has been on the every Barney TV programme or video. Does anyone know a song that is on Barney?

(Demonstrate Michael finishing off a song that we start to sing)

There are some other things that Michael knows, and we're not sure why he likes them but he does.

Q. Who knows what this is? (Hold up book showing Cats - Abyssinian)

Yes it is a cat, yes it is a brown cat. What breed is this cat? ... Watch this!

(Demonstrate Michael naming all the breeds of cats in the Reading Master book)

He also knows lots of names of tropical birds \& New Zealand birds and African animals.

And he knows all of the pictures in this book (similar to PECS, the Picture Exchange Communication System where children show a picture to indicate what they need). 
(Show Michael's communication book and open to the "I need a break" page). He shows his teacher aide this picture when he needs a break, or if he is hungry he shows his teacher or teacher aide his lunchbox card.

Explain to children about the sensory issues that people with autism have. Michael has sensitive ears so the blackboard experiment will give an unpleasant experience for them, similar to what Michael feels when he has sore ears or is anxious, and give some examples of how they can help Michael.

Q. Do you see Michael covering his ears? A lot of children with autism have really sensitive ears. Listen.. (demonstrate scratching down the blackboard with fingernails)

Q. How did that make you feel? (Responses: "Oooo, that hurt my teeth" and "Oooo, it made my whole body feel yuk")

Some people don't like that sound, and that's how we think it is for Michael sometimes. A grown up man with Autism once told me that sometimes the pain he feels in his ears is like when you go to the dentist and they have to drill your teeth, and sometimes they hit a nerve. Has that ever happened to anyone? That really hurts!

Q. Does anyone have any ideas about how we can help Michael when he has sore ears?

Instead of the teacher clapping to get your attention in the classroom, and you clapping back, maybe she can put her arm up, and then you can put your arm up to show her that you're nice and quiet and listening.

Read a story in Māori and a sentence using sign language. It is unlikely that the children will be able to understand what is being said, which is similar to what Michael experiences. Give examples of how we can communicate with him and make up a name for Michael's language.

Sometimes Michael makes loud noises so he doesn't have to hear the noise that other people are making. Do you sometimes hear him? At other times Michael makes noises because he's happy.

Q. Does anyone understand what Michael is saying? (Responses were.. "Not really"?)

Let me introduce you to Nan, she is going to read you a story, and at the end of the story I would like to you tell me what the story was about, so listen carefully.

Nan reads a story in Māori

Q. Did anyone understand what Nan was saying?

Why not? Could you not hear her properly? I heard her.

Now (the teacher aide) is going to speak to you in a different way. When she is finished I want you to tell me what she said.
The teacher aide demonstrates signing, Good morning children, my name is $\mathrm{R} / \mathrm{A} / \mathrm{C} / \mathrm{H} / \mathrm{E} / \mathrm{L}$.

Q. Did anyone understand what she was saying?

Q. Couldn't you see her properly? I could see her. Why can't you tell me what she said?

(Response: "Because she was doing stuff we didn't know")

That's because she also spoke in another language, it's called signing.

Sometimes that's how it is for Michael. He can see your lips moving, but all he can hear is "blah blah blah". He just doesn't understand what you are saying.

Q. Does anyone understand Michael when he is talking?

Maybe sometimes you could play a game and guess what Michael might be saying when he is making a noise.

At home when Michael is talking, sometimes he likes it when I copy him: he looks at me, and sometimes touches my lips to correct me.

Mostly, he likes it when I talk to him in a nice soft voice, and sometimes he talks back to me in his own little language (Demonstrate with Michael).

Q. Does anyone know what language is Michael talking?

I don't know what it is called either but shall we make up a name for it...

The name of some languages are Chinese, Tongan, Fijian, Japanese. What name shall we make up for Michael's language?

(Response: After much debate class decided on "Mike a nese")

When Michael was four years old, he had a book written about him and his sister Samantha. It's called Samantha's Brother (show book) by Julie Ellis.

My friend wrote it, and now its in lots of schools in New Zealand and Australia and America (Leave behind for them to read).

Thank you so much for inviting me into your class today, I'm glad that Michael is in this class. I think Michael is special and I think you are all really special too.

Thanks to Nan, teacher and teacher aide and Michael. Goodbye.

\section{WHAT A BIG DIFFERENCE A SMALL PRESENTATION TO MICHAEL'S CLASSROOM PEERS MADE}

Bernie reports:

The children at Michael's school have always been supportive of him. Our presentation gave them the confidence to interact with Michael and to support him in very practical ways. An added bonus was that many of the children spoke to their parents about Michael. The outcome was that smiles and eye contact towards me as the parent are now more forthcoming. 
Some examples are:

1. The following day after our presentation during a lunch break a police car went past the school with its siren on. Michael stood with his hands covering his ears and a girl in his class came behind him and covered his hands with hers saying "It's OK Michael, it's nearly gone now".

2. When Michael was sitting during a break, three girls came running around the corner then stopped came back and stood in front of Michael and said "Hi Michael, say Hi" to which he replied, "Hi." After this acknowledgement the girls continued on with their activity.

3. When Michael discovered that he liked standing in the middle of the rugby game at lunchtime, the boys would stop and pass Michael the ball. Sometimes he would drop it, and sometimes he would pick it up and run with it (like Forest Gump and not return it!). The boys realised if Michael was to play with them they would need two balls, so they could continue playing if Michael took their ball from the field.

4. We recently took Michael to the school disco and after he finished his packet of chips he went up to another parent, pulled down her hand and gave her the empty packet and skipped off. The parent's shocked face soon turned into a smile after her son ran up to her and said, "hey Mum, that's Michael."

The effect of Bernie's presentation is evident in the stories Michael's classmates wrote following Bernie's visit.

\section{Michael's Story by A}

Today Michael's Mum came and her name is Bernie and we were talking about Michael to see how we could help him. We can play games with him and show him things to do with people and to respect Michael and teach him and we could have a running game or show him how to jump the tyres and Michael's Mum brought some lamps to show us how they work and one was a touch lamp.

\section{Michael's Story by B}

Today Michael's Mum and Nan talked about Michael. How he has autism. If you want Michael to do something give Michael a chip. Michael's Nan read us a story and did you know that some lamps are autistic? Did you know that Michael's ears hurt like a drill in your teeth and did you know that Michael can cook? He likes to cook in Room 5.

\section{Michael's Story by C}

Today Bernie and Nan and Mrs C came in. Bernie talked to us about the problem that Michael has and it starts with A. It's called autism. He has a different brain than us and there are more kids at school with the same thing. Nan also read us a story in Māori. Michael doesn't like light. He also does not like loud noises so we need to turn our voices down. Bernie said Michael is special, then when they started to leave Bernie said that we were special as well.

\section{Michael's Story by D}

Today Michael's Mum came to school to talk to Room 2 about Michael when he is hungry he looks in his little book.

\section{Michael's Story by E}

Today Bernie and Nan came to school to talk to us about Michael and Michael knows the names of lots of cats.

\section{Michael's Story by $\mathbf{F}$}

Today Michael's Mum and Nan came and talked about Michael and Mrs C was doing sign language. Michael's Nan was reading us a story and Michael's Mum brought two lamps and she turned it on and it wasn't on but when she touched it, it went on. Michael was biting his knees and Mrs C brought a black book and Michael's Mum said when Mrs C takes Michael outside she takes the black book with her and then Mrs C gives the book to him and he shows a picture and then she takes him there.

\section{Michael's Story by G}

$\mathrm{Hi}$, we are room 2. Autism is different in some people. $\mathrm{X}$ had autism but Michael has the most.

\section{Michael's Story by $\mathbf{H}$}

Bernie was telling us what autism is, she said Michael has autism. Well I think it is when you can not hear. Michael is a kind boy. He is my friend. He is a nice boy. Sometimes he likes to cover his ears. Michael is a mystery to the scientists and they are trying to find out what autism is, they don't know what it is yet.

Yes, what a big difference a small presentation can make!

\section{APPENDIX 1}

Choosing the right school is a particular concern for many parents of children with ASD because of the additional help their children require. This was a concern Bernie faced a number of years ago. To help her choose the best school for Michael she prepared a set of questions to ask teachers at the schools she visited. These questions centred around the areas that were of major concern and interest to her and relevance to Michael. She explained that some questions had a higher weighting than others - safety for Michael was a high priority. In making the final decision about which school was the "best fit" for her son, Bernie carefully weighed up the information she had gathered. She took into account the answers to her questions, what she had observed, the teachers' attitudes and their willingness to accept and accommodate Michael. She did not expect to find the "perfect" school, but hoped to find one that would seriously consider her concerns and work towards providing the best possible learning environment for her son.

Since then two other Māori parents have helped Bernie refine her original questionnaire. These parents were concerned not only that their children's special needs would be adequately provided for, but also that these needs would be met in a culturally appropriate way in an environment that valued and supported Māori cultural beliefs, values and practices. Below is the latest version of the questionnaire. It is shared in the hopes that it will be useful to other Māori parents who have children with ASD. It is also hoped that the questionnaire will alert educators to a number of parental priorities and concerns. 


\section{Questions Regarding School and School Policies}

1. Does this school have a special needs unit?

2. If so, what percentage of my child's day is likely to be spent in the unit and what percentage of time will they be mainstreamed?

3. What are the benefits of having a special needs unit?

4. If my child is $100 \%$ mainstreamed, what provisions do you have in place for his specific learning needs, sensory issues or behaviours?

5. What experience do your staff have in dealing with children on the autism spectrum?

6. How many children with my child's level of autism, has your current staff dealt with?

7. What type of funding does your school receive for special needs children and how is it used?

8. If my child is classified as having very high or high needs (ORRS funded) how will the funding he attracts be distributed and how many teacher aide hours will be allocated?

9. If my child does not receive any ORRS funding, how will the school deal with? Their specific learning needs, sensory issues, social issues an behaviours?

10. Who will be responsible for my child while he is at your school- e.g., do you have someone who will become familiar with him and his specific needs, and be his advocate especially as he transitions from year to year, or will this responsibility rest on his new teacher each year?

11. Will my child attend school full time?

a) What are the advantages of coming to this school? What are your strengths?

b) Can you see any disadvantages in coming to this school?

12. Is there representation for children with special needs on the Board of Trustees?

\section{Questions Regarding Cultural Issues}

13. What Māori programmes or teaching does this school offer my child?

14. How many Māori teachers or teacher aides are there in this school?

15. Are the teachers, teacher aides, specialists and therapists who work within this school environment knowledgeable or sensitive to Māori cultural needs/tikanga?

16. Is the school open to input or increasing their awareness of Māori cultural needs?

17. Is there Māori representation on the Board of Trustees and PTA?

18. What relationship does the school have with the Māori Community and how is this relationship maintained?

19. Do you have a kapa haka group in this school, and is my child able to join?

20. Will there be a pōwhiri to welcome my child and our whānau into this school?

21. Is there an expectation that my child will participate in all activities in regards to our Māori culture? (e.g. pōwhiri, kapa haka, marae visit, tangi)
22. If my child needs assistance in toileting, dressing or showering, will you make allowances regarding physical handling which is sensitive to cultural needs?

23. What is your policy regarding use, storage and administering of Rongoa? (Māori medicine)

24. Are your school and your staff prepared to cater for or make allowances for our cultural needs in regards to karakia (prayer) before eating?

25. Who is my child likely to have as his teacher aide? What is their experience and training relevant to Māori and ASD?

26. Are my whānau able to attend IEPs and other school meetings and if so, do you have the facilities to cater for them?

\section{Questions Regarding Learning Outcomes}

27. Are there any particular programmes you have in place specifically for children with ASD, and how successful are they?

28. What programmes are you likely to implement for my child?

29. Is there ongoing training or professional development about ASD? Who is likely to participate in this training?

30. What type of specialists do you use in this school and how often do you meet with them?

31. Will my child be included in all the school activities?

32. What alternatives are in place if my child is unable to attend any of the school activities/outings?

\section{Questions Regarding Family/Whānau}

33. Do you encourage parental input, particularly regarding behavioural issues and learning outcomes?

34. Do parents have the opportunity to meet with the teacher aide/s who are likely to be spending the most time with my child?

35. What protocols will you use for communication between the teacher, teacher aide, parents and whānau?

36. If parents have a complaint, what procedures do you have in place for hearing these complaints?

37. If a programme has been successful at home, is the school open to adapting their school programmes in light of this programme?

\section{Questions Regarding School Environment}

38. Who will be with my child at intervals and lunchtimes, and where is this likely to be?

39. If my child needs assistance in toileting, dressing or showering:

a) Do you have suitable facilities?

b) What is your policy regarding physical handling of my child?

c) Who will be responsible for the above?

40. How many children are in my child's class or special needs unit? What are the class sizes likely to be as he/she progresses? 


\section{Other Things a Parent may Need to Observe and Consider:}

41. Geographical placement of the school: For example, is my child going to be at risk if the school is on a main road, or intersection? If my child is considered a runner, how many exits are there to the school, and what are the potential risks in the neighbourhood if he manages to escape?

42. If my child is a climber, are the fences high enough, or are there apparatus that can be used as a ladder?

43. If my child puts everything in his/her mouth, are there any obvious poisons or poisonous plants which are within my child's reach?

44. When potential hazards are identified by parents/ whānau, are the school prepared to make necessary alterations to suit my child's needs?

\section{AUTHOR PROFILES}

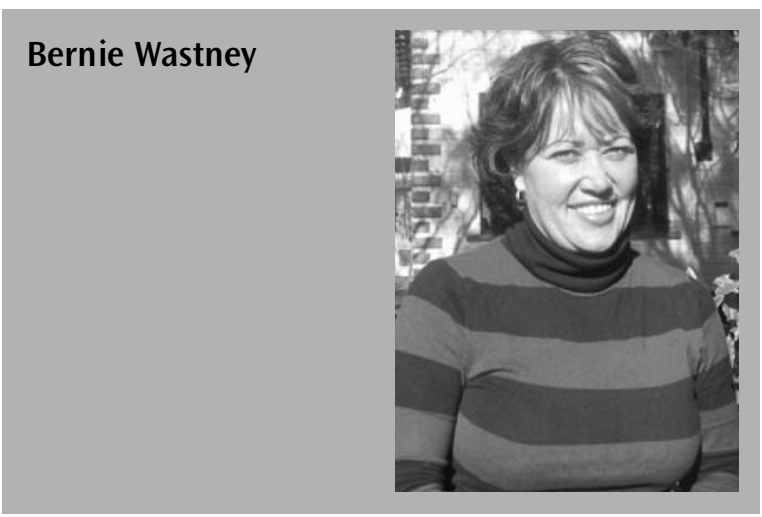

\section{Bernie Wastney}

Bernie Wastney is the mother of Michael who has severe autism. She has read extensively in the area of ASD and is an active parent advocate. She is a trustee of the PAI 4 ASD Trust (Promotion of Acceptance and Inclusion of Autism Spectrum Disorder - Te Hapaitanga o te Whakaaetanga Trust). Her iwi affiliation is Ngāti Porou and Kahungunu.

\section{Email}

grahamwastney@clear.net.nz

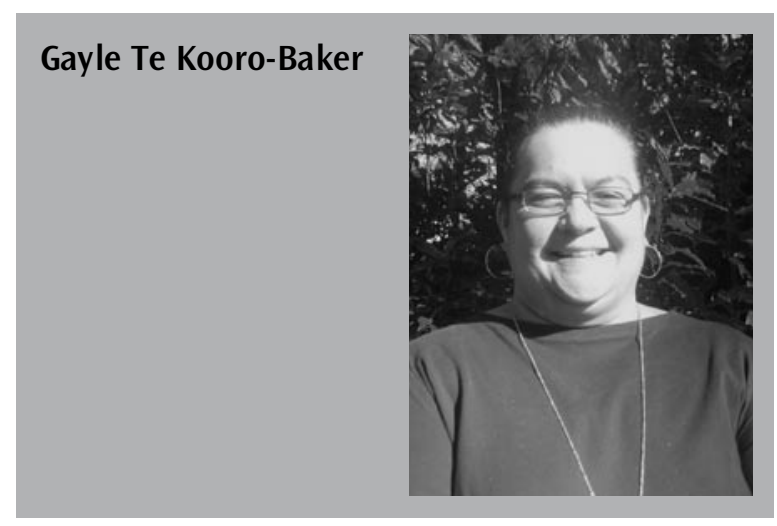

\section{Gayle Te Kooro-Baker}

Gayle Te Kooro-Baker is the mother of two boys with Aspergers syndrome. Her tribal affiliations are Ngāti Raukawa, Te Ati awa and Ngāti Ruanui. Her children also whakapapa to the Cook Islands through their father, Daniel. Gayle is a trustee of the PAI 4 ASD Trust (Promotion of Acceptance and Inclusion of Autism Spectrum Disorder Te Hapaitanga o te Whakaaetanga Trust). She is a past Board of Trustees member and is actively involved in her children's school's Pasifika group.

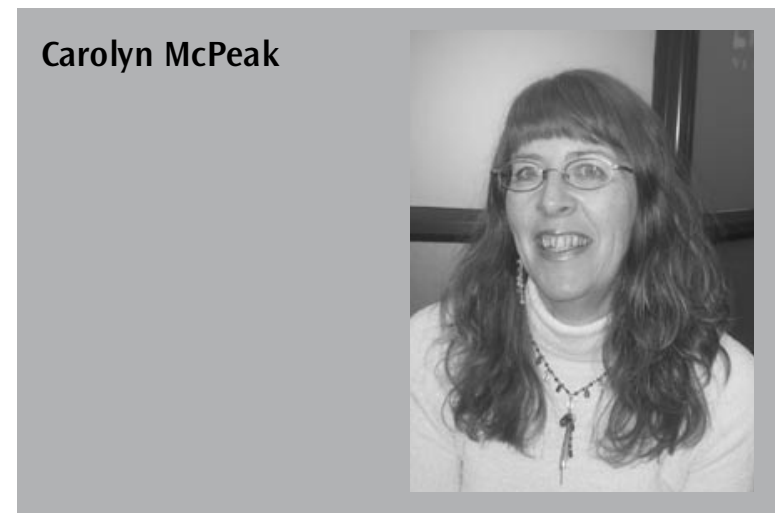

\section{Carolyn McPeak}

Carolyn McPeak is the mother of an adult son with Asperger syndrome. She was the founding Chairperson of the Autistic Association branch in the Manawatu. Tribal affiliation is Ngāti Raukawa (Ngāti Huri). Carolyn currently works for Supportlinks as a Needs Assessor/Coordinator.

\section{Email}

carolyn964@hotmail.com 